\title{
Ege Üniversitesi Hastanesinde glioblastomaların epidemiyolojik ve sağ kalım özellikleri
}

\section{Epidemiological and survival features of glioblastomas in Ege University Hospital}

\author{
Meltem Öztürk ${ }^{1}$ Serra Kamer Keşim Ertan $^{1}$ (D) Erkin Özgiray ${ }^{3}$ (D) \\ Taşkın Yurtseven $^{3}$ Ulus Ali Şanlı, $\quad$ Uld $\quad$ Ayfer Haydaroğlu $^{1}$ \\ ${ }^{1}$ Ege Üniversitesi Tıp Fakültesi, Radyasyon Onkolojisi Anabilim Dalı, İzmir, Türkiye \\ ${ }^{2}$ Ege Üniversitesi Tıp Fakültesi, Tıbbi Patoloji Anabilim Dalı, İzmir, Türkiye \\ ${ }^{3}$ Ege Üniversitesi Tıp Fakültesi, Beyin ve Sinir Cerrahisi Anabilim Dalı, İzmir, Türkiye \\ ${ }^{4}$ Ege Üniversitesi Tıp Fakültesi, Medikal Onkoloji Bilim Dalı, İzmir, Türkiye \\ ${ }^{5}$ Ege Üniversitesi Kanserle Savaş ve Araştırma Merkezi (EUKAM), İzmir, Türkiye
}

Öz

Amaç: Ege Üniversitesi Hastanesi (EÜH) veri tabanındaki 1327 Glioblastoma (GBM) olgusunun epidemiyolojik ve genel sağ kalım (GSK) özelliklerini istatistiksel açıdan değerlendirmektir.

Gereç Yöntem: EÜ Kanserle Savaş Uygulama ve Araştırma Merkezi (EÜKAM) tarafından 1992-2017 arasında kanser veri tabanında toplanan 117139 kanser verisi içindeki 1327 GBM olgusu değerlendirilmiştir.

Bulgular: 1327 GBM hastası analiz edilmiştir. Tanı anı ortalama yaş 55,6 yıl bulunmuştur. Erkek/kadın oranı 1,52:1'dir. En sık tutulumun temporal lobta $(\% 36,3)$ olduğu saptanmıştır. Tedavisi raporlanan 881 hastanın analizinde; olguların \%30,2'sine yalnızca operasyon, \%65,6'sına kombine tedaviler uygulanmıştır. Otuz beş hastada $(\% 4,0)$ yalnızca radyoterapi $(R T)$ uygulanırken 558 hastada $(\% 63,3)$ kombine tedavide RT eklenmiştir. Tüm GBM hastalarının ortalama sağ kalım süresi 12,15 aydır. Bir, iki, üç ve beş yıllık GSK oranları sırasıyla $\% 50,4, \% 22,02, \% 11$ ve $\% 5$ 'tir. Ortalama sağ kalım erkeklerde 11,6 ay, kadınlarda 13,3 ay olarak saptanmıştır. Cinsiyet ile sağ kalım süresi arasında anlamlı ilişki saptanmamıştır. Yaş gruplarına göre sağ kalım analizinde ileri yaş gruplarında sağ kalımın anlamlı olarak azaldığı saptanmıştır $(p<0,001)$. Cerrahi, RT ve kemoterapi (KT) uygulanan hastaların bir ve beş yıllık GSK oranının diğer tedavi şekillerine göre daha yüksek olduğu saptanmıştır $(p<0,001)$. Ortalama sağ kalım RT alan grupta 14,0 ay, almayanlarda ise 9,4 ay olarak bulunmuştur $(p<0,001)$.

Sonuçlar: Çalışmamızda tanı yaşı, eşzamanlı ve adjuvan KT (Temozolomid) tedavisi sağ kalımı etkileyen prognostik faktörler olarak bulunmuştur. Cinsiyet ve tümör lokalizasyonu ile sağ kalım arasında anlamlı fark saptanmamıştır. Günümüzde maksimum cerrahi rezeksiyon ve ardından adjuvan kemoradyoterapi, GBM yönetiminin temel standardı olup, ortalama 12 aylık GSK sağlamaktadır.

Anahtar Sözcükler: Beyin tümörleri, glioblastoma, radyoterapi

\section{Abstract}

Aim: The aim of this study was to evaluate the epidemiological and overall survival rates(OS) of 1327 cases of Glioblastoma (GBM) in Ege University Hospital (EÜH) database.

Materials and Methods: 1327 GBM cases were evaluated in 117139 cancer data collected from the cancer database between 1992 and 2017 by the EU Cancer Control Application and Research Center.

\footnotetext{
Yazısma Adresi: Serra Kamer

Ege Üniversitesi Tıp Fakültesi, Radyasyon Onkolojisi

Anabilim Dalı

E-mail: serrakamer@gmail.com
} 
Results: 1327 GBM patients were analyzed. The mean age at diagnosis was 55.6 years. The male/female ratio was 1.52:1. The most common involvement was found in temporal lobe (36.3\%).In analysis of 881 patients whose treatment was reported. In $30.2 \%$ of the cases, only operation was performed and in $65.6 \%$ combined treatments were applied. RT was added in 558 patients (63.3\%). The ortalama survival time of all GBM patients was 12.15 months. One, two, three and five-year OS rates were $50.4 \%, 22.02 \%, 11 \%$ and $5 \%$ respectively. Ortalama survival was 11.6 months for males and 13.3 months for females No significant difference was found between sex and survival time. Survival analysis signify that survival decreased in older age groups $(p<0.001)$. Patients who was treated with surgery, RT and chemotherapy (CT) were found to have a higher 1 and 5-year OS rate compared to other treatment modalities $(p<0.001)$. Ortalama survival was 14.0 months in $R T$ group and 9.4 months in non-RT group $(p<0.001)$.

Conclusions: Age of diagnosis, concurrent and adjuvant chemotherapy (Temozolomide) were found to be prognostic factors affecting survival. There was no significant difference between sex and tumor localization and survival. Maximum surgical resection followed by adjuvant chemoradiotherapy is the basic standard of GBM management and provides an average of 12 months OS.

Keywords: Brain tumors, glioblastoma, radiotherapy

\section{Giriş}

Glioblastoma (GBM) erişkinlerde en sık görülen primer malign beyin tümörüdür ve malign gliomaların yaklaşık \%80'ini oluşturur $(1,2)$. GBM'nin ortalama insidans hızı 3.19/100.000 ve ortalama tanı yaşı 64 'tür. GBM'de birçok genetik ve çevresel faktör çalışılmıştır ancak çoğunluğu sporadiktir ve GBM ile ilişkili net bir risk faktörü tanımlanmamıştır. Bununla birlikte, tanı sırasındaki genç yaş, serebellar yerleşim yeri, yüksek performans durumu ve maksimal tümör rezeksiyonu dahil olmak üzere birçok klinik prognostik faktör tanımlanmıştır. GBM'ler, farklı genetik yollardan gelişen, farklı yaşlarda hastaları etkileyen ve sonuçlarında farklılıklar bulunan birincil ve ikincil alt tiplerden oluşur. Birincil (de novo) GBM'ler GBM'lerin \%80'ini oluşturur ve daha yaşlı hastalarda görülür (ortalama 62 yaş). İkincil GBM'ler düşük dereceli astrositom veya oligodendrogliomalardan gelişir ve daha genç hastalarda (ortalama yaş 45) ortaya çıkar (13). Yeni tanı konmuş GBM hastalarının klinik şikayetleri tümör lokalizasyonuna ve büyüklüğüne bağlıdır. Hastalar genellikle baş ağrısı, baş dönmesi, mide bulantısı, uyuşukluk, nöbet, hemiparezi, görme kaybı, hafıza problemleri veya kişilik değişikliği ile başvururlar (2). Nöbet, yüksek dereceli gliomalı hastaların \%30-\%50'sinde ortaya çıkan semptomdur. Standart tedavi maksimum cerrahi rezeksiyonu takiben eş zamanlı kemoterapi (temozolomid) ile adjuvan radyoterapi, ardından adjuvan kemoterapi olmuştur. Adjuvan temozolomid tedavisine hastalık progresyonu olmadıkça en az altı ay devam edilmektedir (4). Definitif tedavi sonrası nükslerde ya da tedavi başarısızlığı durumunda bevacizumab kurtarma tedavisi olarak kullanılabilmektedir. Kemoterapi kullanılamayan nüks hastalarında radyocerrahi, yoğunluk ayarlı radyoterapi (IMRT), brakiterapi gibi radyoterapötik stratejiler düşünülebilir. Yıllar içinde değişen tedavi yaklaşımlarına rağmen hastaların sağ kalım oranlarında istenen başarı elde edilememiştir. Ortanca sağ kalım oranları 912 ay, iki yıllık sağ kalım oranı ise \%8-12 arasında değişmektedir (2). Sağ kalımı etkileyen prognostik faktörler; yaş, performans durumu, kemoterapi uygulaması, toplam radyoterapi dozu ve cerrahi rezeksiyonun genişliği olarak tanımlanmaktadır $(1,6)$.

\section{Gereç ve Yöntem}

EÜ Kanserle Savaş Uygulama ve Araştırma Merkezi (EÜKAM) tarafından 1992-2017 arasında kanser veri tabanında toplanan 117139 kanser verisi CANREG özel bilgisayar programına kaydedilmiştir. Bu olgular içindeki 881 olgu değerlendirilmiştir. İstatistik analizlerde Ki-kare, General Linear Model (GLM), Kaplan Meier sağ kalım analizleri uygulanmıştır. Kaplan Meier sağ kalım analizinde Log Rank (MantelCox), Breslow (Generalized Wilcoxon) ve Tarone-Ware istatistikleri kullanılmıştır. İstatistik analizlerde $p<0,05$ anlamlı kabul edilmiştir.

\section{Bulgular}

EÜH kanser veri tabanındaki 5877 Merkezi sinir sistemi (MSS) tümörleri içinde en büyük gurubu 3876 olgu (\%63) ile diffüz astrositomalar ve oligodendrogliomalar oluşturmaktadır (Şekil-1). Bu grubun içinde 1327'si GBM'lerdir (Şekil-2). Çalışmamızdaki hasta özellikleri Tablo-1'de gösterilmiştir. 


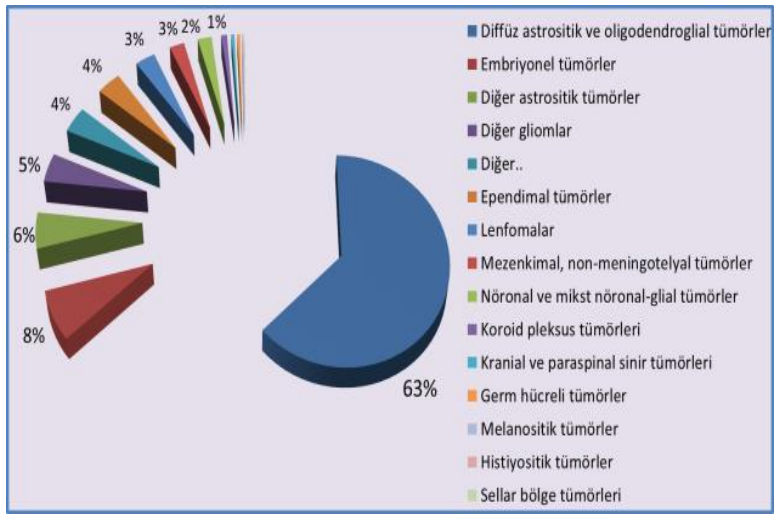

Şekil-1. MSS tümörleri yüzdelik dağılım.

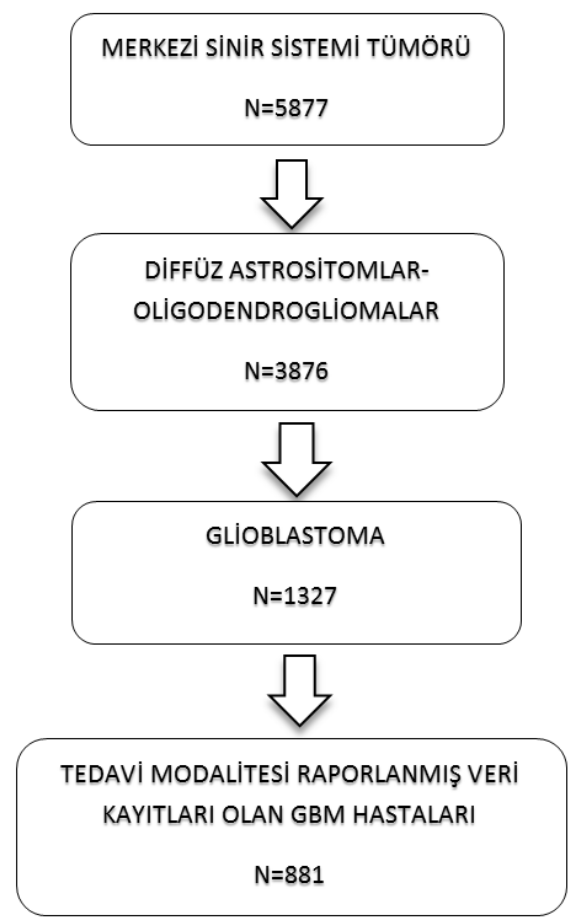

Şekil-2. İncelemede hasta seçimini gösteren akış diyagramı.

Olguların \%60,4'ü erkek, \%39,6'sı kadın ve erkek/kadın oranı 1,52:1'dir (Şekil-3). Tanı anı ortalama yaş 55,6 yıl (aralık $0-89$ yıl) bulunmuştur. Erkeklerde en çok \%30,5 oranında 50-59 yaş arasında, kadınlarda ise \%31,6 oranıyla 60-69 yaş arasında görülmektedir (Şekil 4). Yerleşim yeri raporlanan 782 hasta analiz edildiğinde en sık tutulumun temporal lobta $(\% 36,3)$ olduğu saptanmıştır (Şekil-5). Tedavi modeli raporlanan 881 hastanın analizinde; olguların \%30,2 sine yalnızca operasyon, $\% 65,6$ 'sına ise kombine tedaviler uygulanmıştır. Otuz beş hastada $(\% 4,0)$ yalnızca radyoterapi (RT) uygulanırken 558 hastada $(\% 63,3)$ kombine tedavide RT eklenmiştir. Genel doğrusal model analizinde GBM yerleşimlerin yıllara göre dağılımları incelendiğinde, tüm yerleşimlerde doğrusal artış saptanmış ancak yıllara dağılım oranlarındaki artış anlamlı bulunmamıştır. (Yıllara Göre Değişim Glm F=3,836; $p=0,010$ ) (Şekil-6).

Tablo-1. Hasta özellikleri.

\begin{tabular}{|c|c|c|}
\hline Ozellik & vaka & \% \\
\hline Yaş Grubu (yıl) & 1327 & \\
\hline $0-9$ & 17 & 1,3 \\
\hline $10-19$ & 27 & 2 \\
\hline $20-29$ & 46 & 3,5 \\
\hline $30-39$ & 89 & 6,7 \\
\hline $40-49$ & 197 & 14,8 \\
\hline $50-59$ & 387 & 29,2 \\
\hline $60-69$ & 378 & 28,5 \\
\hline$>70$ & 186 & 14 \\
\hline Median yaş (aralık) & $55,6(0-89)$ & \\
\hline \multicolumn{3}{|l|}{ Cinsiyet } \\
\hline Kadın & 526 & 39,6 \\
\hline Erkek & 801 & 60,4 \\
\hline \multicolumn{3}{|l|}{ Tümör lokalizasyonu } \\
\hline Frontal & 246 & 31,5 \\
\hline Pariyetal & 195 & 24,9 \\
\hline Oksipital & 57 & 7,3 \\
\hline Temporal & 284 & 36,3 \\
\hline \multicolumn{3}{|l|}{ Tedavi modalitesi } \\
\hline Yalnız operasyon & 266 & 30,2 \\
\hline Yalnız KT & 3 & 0,3 \\
\hline Yalnız RT & 35 & 4 \\
\hline$O p+R T$ & 372 & 42,2 \\
\hline$O p+K T$ & 19 & 2,2 \\
\hline$R T+K T$ & 19 & 2,2 \\
\hline$O p+R T+K T$ & 167 & 19 \\
\hline \multicolumn{3}{|l|}{ Takip süresi (Ay) } \\
\hline Median (aralık) & $12,15(0-229)$ & \\
\hline
\end{tabular}

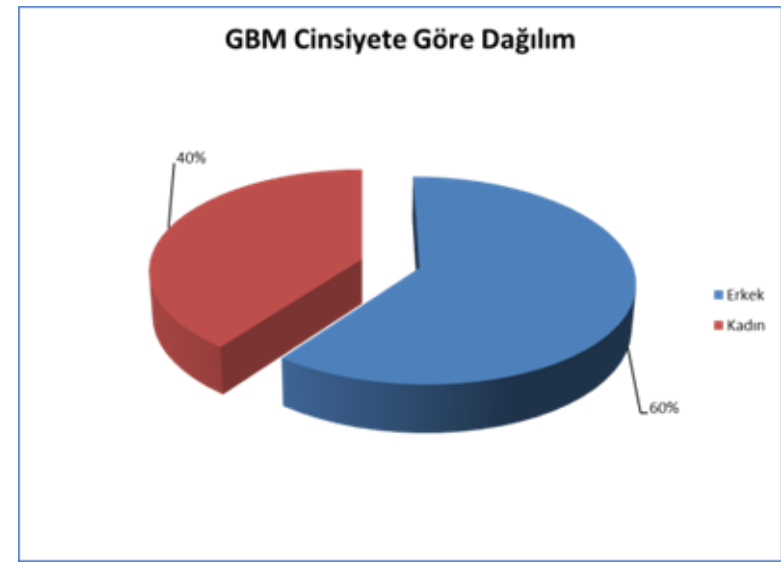

Şekil-3. Cinsiyetlere göre dağııım. 


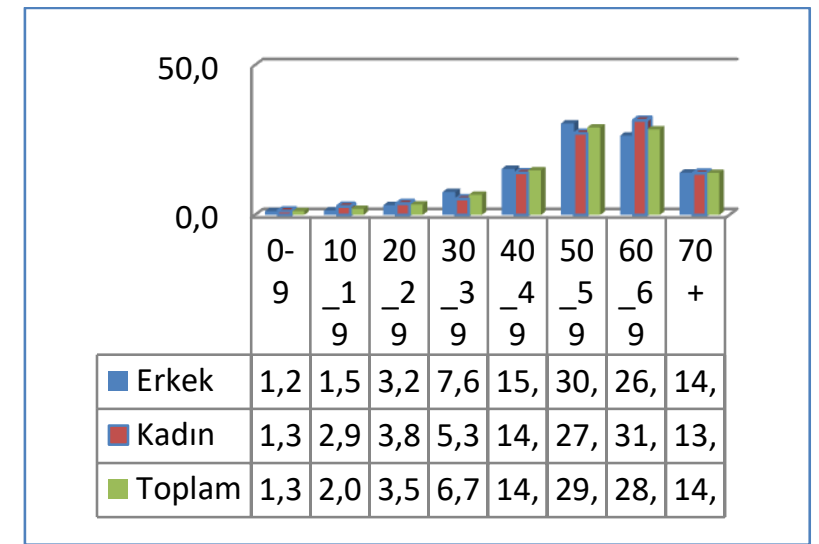

Şekil-4. Cinsiyet ve yaş gruplarına göre dağııım.

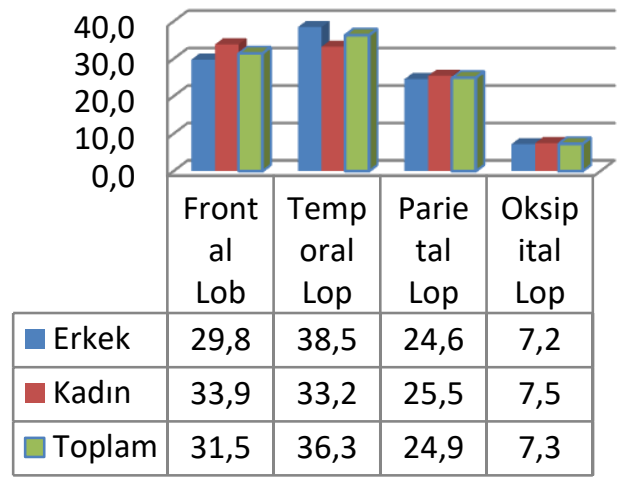

Şekil-5. Cinsiyet ve yerleşim yerine göre dağııım.

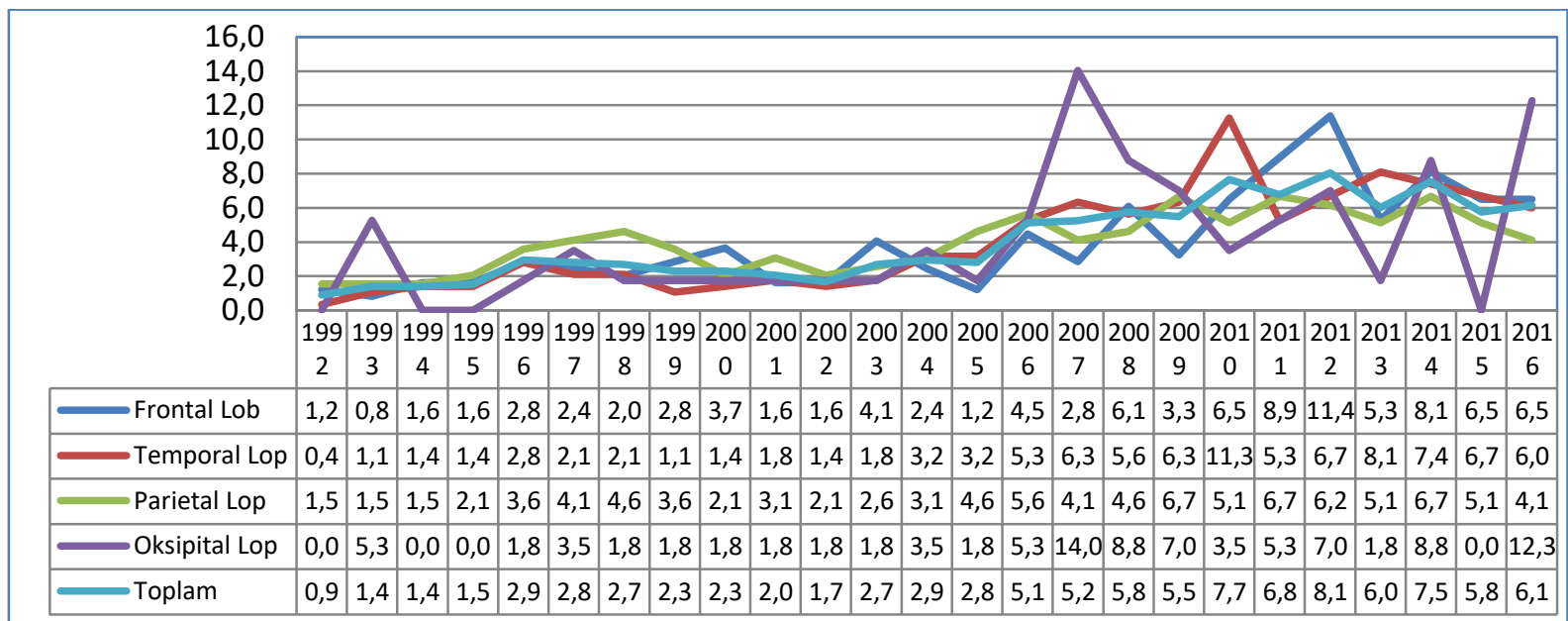

Şekil-6. GBM yerleşiminin yıllara göre değişimi

Sağ kalım: Tüm GBM hastalarının ortalama sağ kalım süresi 12,15 aydır. Bir, iki, üç ve beş yıllık genel sağ kalım oranları sırasıyla $\% 50,4, \% 22,02$, $\% 11$ ve \%5'tir (Şekil-7). Ortalama sağ kalım erkeklerde 11,6 ay, kadınlarda 13,3 ay olarak saptanmıştır (Wilcoxon (Gehan) Statistic $=0,782$ $\mathrm{p}=0,372)$. 2 ve 5 yıllık genel sağ kalım oranları sırasıyla erkeklerde \%21,1 ve \%4,5 iken kadınlarda \%24 ve \%5,8'tir (Şekil-8).

Cinsiyet ile sağ kalım süresi arasında anlamlı ilişki saptanmamıştır. Tümör lokalizasyonu cinsiyetler arasında anlamlı fark göstermemiştir. (Kikare=2,515 $p=0,475$ ) Yerleşim yeri sağ kalım ilişkisi arasında da anlamlı fark bulunmamıştır. (Wilcoxon (Gehan) Statistic $p=0,39$ ) (Tablo-2) Yaş gruplarına göre sağ kalım analizi yapıldığında, ortalama sağ kalım 20-29 yaş aralığında \%22,36 ile en yüksek olup, ileri yaş gruplarında sağ kalımın anlamlı olarak azaldığı saptanmıştır. (Wilcoxon (Gehan) Statistic $p<0,001$ ) (Şekil-9).

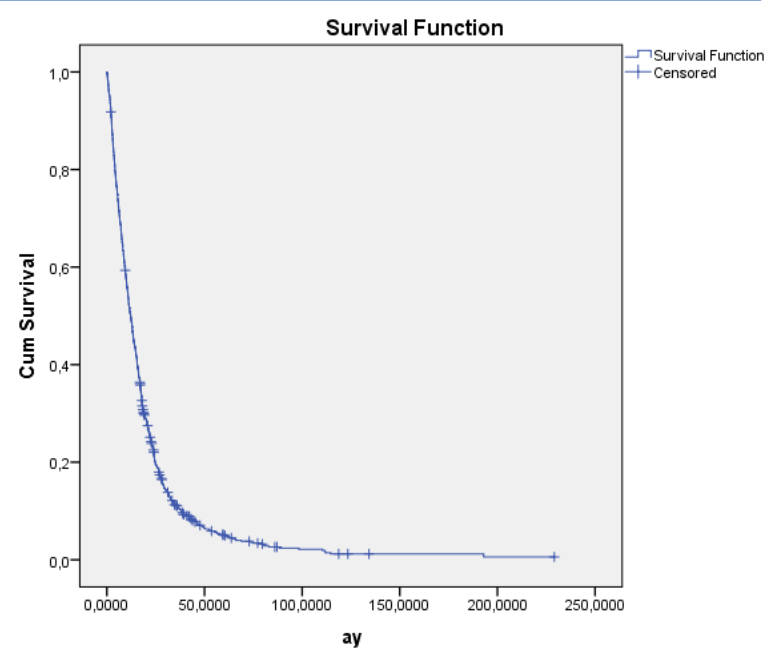

Şekil-7. Genel sağ kalım eğrisi. 


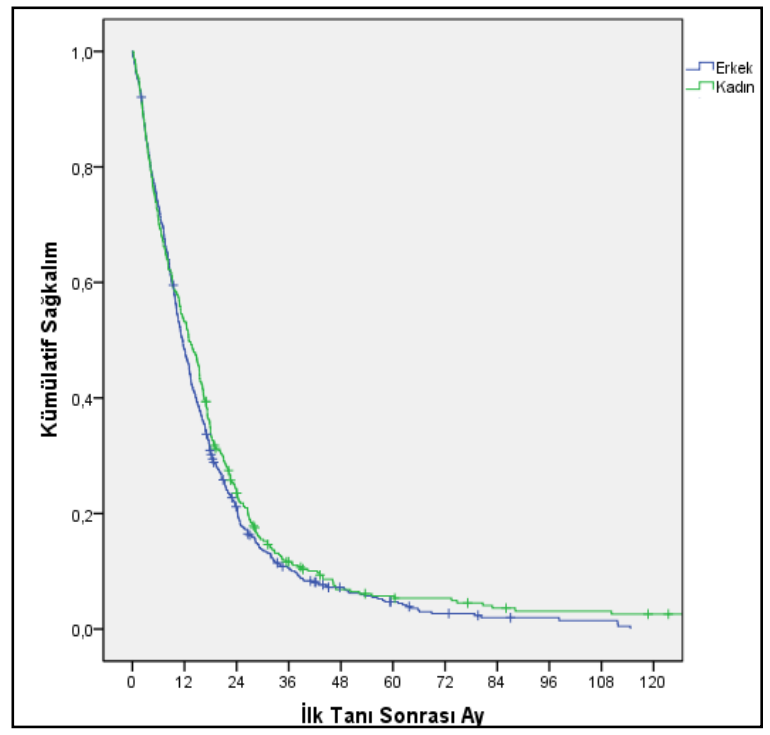

Şekil-8. Cinsiyetlere göre sağ kalım eğrisi

Tablo-2. Yerleşim yeri sağ kalım ilişkisi.

\begin{tabular}{|l|c|}
\hline Yerleşim Yeri & Median sağ kalım (ay) \\
\hline Frontal Lob & 12,19 \\
\hline Temporal Lop & 14,05 \\
\hline Parietal Lop & 13,48 \\
\hline Oksipital Lop & 11,45 \\
\hline
\end{tabular}

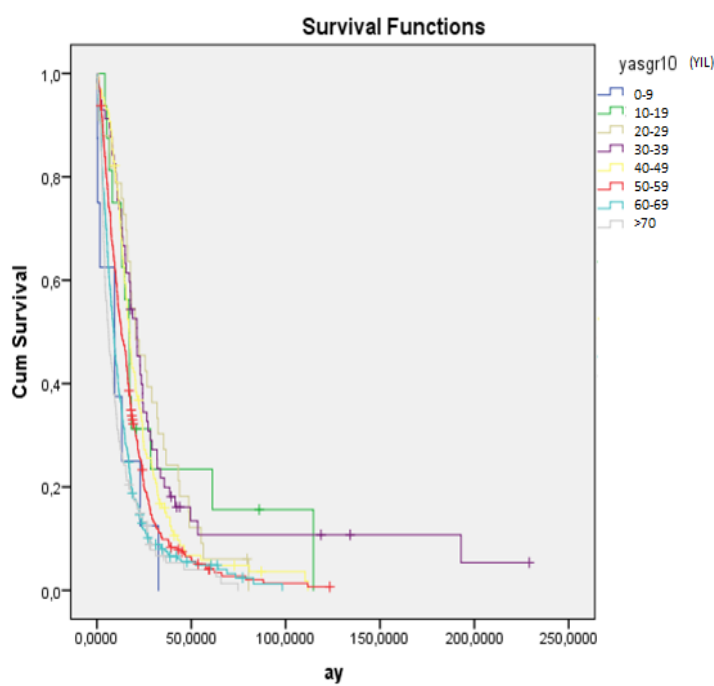

Şekil-9. Yaş gruplarına göre sağ kalım eğrisi.

Cerrahi tedavi, radyoterapi ve kemoterapi (KT) uygulanan hastaların 1 yıllık sağ kalım oranının diğer tedavi şekillerine göre daha yüksek olduğu saptanmıştır. Beş yıllık GSK yalnız operasyon uygulanan grupta \%5,9, postoperatif RT uygulanan grupta \%3,8 ve postoperatif eşzamanlı KT ve RT alan grupta \%6,5 olarak saptanmıştır (Tablo 3). On yıllık GSK ise sırasıyla \%1,7, \%3,8 ve \%3,6'dır (Wilcoxon (Gehan) Statistic $=57,010$ $\mathrm{p}<0,001$ ) (Şekil-10). Ortalama sağ kalım RT alan grupta 14,0 ay, almayanlarda ise 9,4 ay olarak bulunmuştur (Wilcoxon(Gehan) Statistic $=49,310$ $p<0,0001)$ (Şekil-11).

Tablo-3. Tedavi modalitelerine göre 1, 2, 4, 5 ve 10 yıllık GSK yüzdeleri

\begin{tabular}{|l|c|c|c|c|c|c|c|}
\hline & $\mathbf{N}$ & $\begin{array}{l}\text { Yasayan } \\
(\%)\end{array}$ & $\begin{array}{l}12 \text { ay } \\
(\%)\end{array}$ & $\begin{array}{l}24 \text { ay } \\
(\%)\end{array}$ & $\begin{array}{c}48 \text { ay } \\
(\%)\end{array}$ & $\begin{array}{c}60 \text { ay } \\
(\%)\end{array}$ & $\begin{array}{c}120 \text { ay } \\
(\%)\end{array}$ \\
\hline $\begin{array}{l}\text { Yalniz } \\
\text { Operasyon }\end{array}$ & 266 & 4,5 & 33,7 & 17,1 & 6,4 & 5,9 & 1,7 \\
\hline $\begin{array}{l}\text { Kombine } \\
\text { OP+RT }\end{array}$ & 372 & 4,6 & 58,3 & 23,5 & 7,2 & 3,8 & 0,6 \\
\hline $\begin{array}{l}\text { Kombine } \\
\text { OP+RT+KT }\end{array}$ & 167 & 10,2 & 62,9 & 32,2 & 8,7 & 6,5 & 3,6 \\
\hline
\end{tabular}

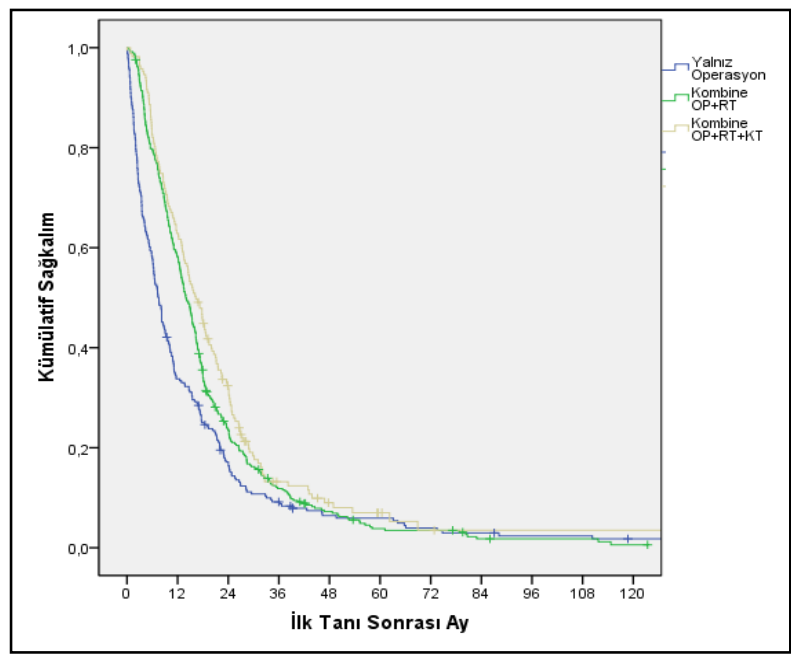

Şekil 10. Tedavi modalitelerine göre sağ kalım eğrisi

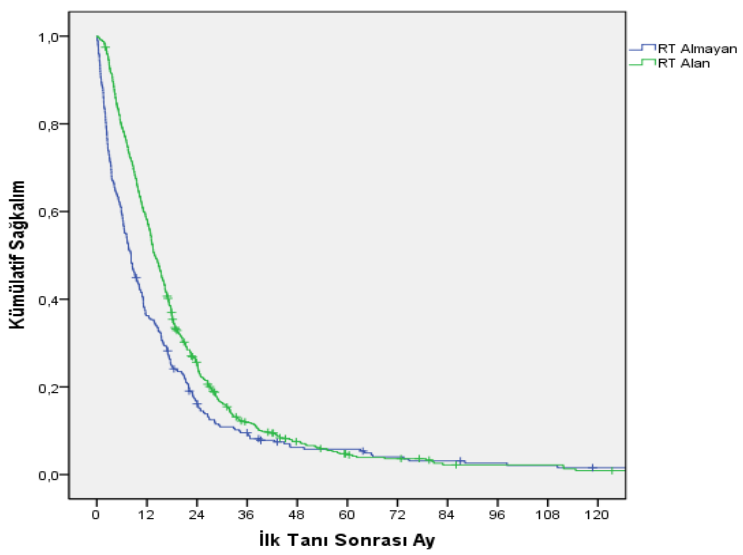

Şekil-11. RT alan ve almayan grupta sağ kalım eğrisi 


\section{Tartışma}

2018 yılı Dünya geneli kanser istatistiklerinde yeni tanı alan kanser hastalarının \%1,38'i beyin ve sinir sistemi tümörleri tanısı almıştır. 20102014 yılları arası ülkemiz verilerine bakıldığında beyin tümörleri oranı $\% 2,3$ olarak saptanmıştır. EÜKAM tarafından 1992-2017 yılları arasında kanser veri tabanında toplanan 117139 kanser verisinde ise beyin tümörlerinin oranı $\% 5$ olarak bulunmuştur.

Bu çalışmada; ortalama 12,15 ay takip süreli tek bir kuruma ait verilere dayanan geriye yönelik bulgular sunulmuştur. Çalışma sonuçları GBM'de yıllar içinde hasta özellikleri ve sağ kalım sonuçlarını irdeleyen çalışma sonuçları ile benzerlik göstermektedir $(9,10)$. GBM multimodal tedaviye rağmen en kötü prognozlu beyin tümörüdür. İyi bilinen epidemiyolojik gerçekler, açıkça GBM hastalarının çoğunun nispeten kısa bir genel sağ kalıma sahip olduğunu ve nadiren bazılarının üç yıldan daha uzun süre hayatta kalabildiğini göstermektedir $(9$, 10).

GBM'de ilk tedavi maksimum güvenli rezeksiyon şeklinde yapılan cerrahi tedavidir. Cerrahiye RT eklenmesi sağ kalımı 4-5 aydan 9-12 aya yükselttiğinin gösterilmesinin ardından (2), 2005 yılında kemoterapinin tedaviye eklenmesinin avantajı da ortaya konmuştur. Stupp ve arkadaşlarının eşzamanlı kemoradyoterapinin iki yıllık sağ kalımda yaklaşık iki kat artış sağlayan tedavi yaklaşımı tanımlamasının ardından; standart tedavi cerrahi sonrası postoperatif RT ile eş zamanlı temozolomid (TMZ) ve ardından adjuvan TMZ olarak kabul edilmektedir. Her iki kol için iki yıllık ve beş yıllık sağ kalım oranları sırasıyla $\% 27,2$ ve $\% 9,8, \% 10,9$ ve $\% 1,9$ raporlanmıştır (4). Witthayanuwat ve ark. GBM tanısı alan 77 hastayı geriye yönelik incelemiştir. Çalışmalarında ortalama yaş 53 (4-76 yaş arası), ortalama sağ kalım süresi 12 ay olarak bildirilmektedir ve alt grup analizinde postoperatif RT eklenen grupta ortalama sağ kalım 11 ay, iki yıllık sağ kalım oranı \%17,2 iken postoperatif RT ile eşzamanlı TMZ tedavisi alan grupta 23 ay ve $\% 38,2$ bulunmuştur (5). Çalışmamızda 167 hastanın $(\% 10,2)$ eş zamanlı kemoterapi aldığı tespit edilmiştir ve eşzamanlı KT almış olan hastalarda eşzamanlı KT almayanlara göre ortalama sağ kalımda anlamlı bir fark olduğu kaydedilmiştir $(p<0,001)$. Eşzamanlı KT alan hastalar arasında iki yıllık sağ kalım \%32,2 iken, almayanlarda bu oran \%23,5 bulunmuştur.
Çalışma sonuçları kemoterapi ve radyoterapi birlikteliğini irdeleyen çalışma sonuçları ile benzerlik göstermektedir $(4,5)$.

Uzun sağ kalım gösteren GBM hastalarının demografik özellikleri çeşitli çalışmalarda irdelenmiştir. Johnson ve arkadaşları 2012 yılında GBM'de hayatta kalma oranının bir analizini yayınlamışlar ve hastaların \%6,2'sinde 5 yıllık GSK'ye ulaşıldığını ve bunlar arasında ek 5 yıl hayatta kalma olasılığının yaklaşık \%45 olduğunu bulmuşlardır $(3,7)$. Polley ve ark. yeni tanı konmuş GBM hastalarında yedi faz II çalışma temelinde benzer bir karşılaştırma yapmışlardır. Hayatta kalma olasılıklarının tanıdan sonraki ilk 2 yılda en hızlı şekilde azaldığını ve sonraki yıllarda sabit kaldığını tespit etmişlerdir. Bu çalışmadaki ana sonuç zaman içinde ölümcül olmayan bir ölüm tehlikesi olduğunu göstermektedir ve 2 yıllık genel sağ kalımdan sonraki prognoz ilk 24 ay içinde olduğundan farklı ve daha elverişlidir $(3,8,9)$.

Tykocki ve ark. yayınladıkları derlemede GBM'de on yıldan uzun süre devam eden çok uzun sağ kalım hakkında kümülatif veriler sunmuştur. CBTRUS (Central Brain Tumor Registry of the United States) istatistik raporunda 1995-2007 yılları arasında 30611 GBM vakasından elde edilen veriler ele alınmış, 5 ve 10 yıllık sağ kalım oranının sırasıyla $\% 5$ ve $\% 2,6$ olduğu gösterilmiştir. Çalışmamızda 1, 2, 5 ve 10 yıllık genel sağ kalım literatürdekilere benzer şekilde sırasıyla $\% 50,4, \% 22,0, \quad \% 5$ ve $\% 1,2$ olarak bulunmuştur.

CBTRUS analizinde 10 yıllık GSK, 0-14, 15-39 ve $40+$ yaş gruplarında sırasıyla $\% 14,9, \% 13,6$ ve $\%$ 1,6 bulunmuştur. Bu çalışmada bulunan bir başka önemli nokta, tanıdaki yaşın küçüldükçe genel sağ kalımın o kadar uzun olduğunu doğrulamasıdır (3). Abacıoğlu ve ark. 2004 yılında yayınladıkları çalışmada 60 yaş ve üzeri olmanın hem tek değişkenli hem de çok değişkenli analizde sağ kalım üzerine olumsuz prognostik faktör olduğu gösterilmiştir (14). Literatürde yaşın prediktif değeri defalarca kanıtlanmıştır (1). Bizim verilerimizde de en yüksek ortalama sağ kalım oranı $\% 20,42$ ile 20 29 yaş aralığındaki hastalarda bulunmuş olup yaşla birlikte ortalama sağ kalım oranları azalmıştır.

Malign gliomalarda tedavilerdeki gelişmelere paralel olarak GSK oranlarının son on yılda yavaşça iyileştiğine dikkat edilmelidir (10). Yeni tedavilerin sağladığı en büyük sağ kalım 
yararları, 1960 'larda ve 1970 'lerde tanı alan hastalarda meydana gelmiştir. Sağ kalımı olumlu etkileyen faktörler, adjuvan kemoterapi ile radyoterapi, nörolojik görüntülemedeki gelişmeler, klinik uygulama ve modern cerrahi teknolojilerinin geliştirilmesini içermektedir. Multimodalite tedavisi en etkin tedavi sonucu sağlarken, TMZ sağ kalım süresini uzatmak için GBM hastalarında oldukça faydalıdır $(11,12)$.

\section{Sonuç}

Çalışmamızda tanı yaşı, eşzamanlı ve adjuvan TMZ tedavisi sağ kalımı etkileyen prognostik faktörler olarak bulunmuştur. Cinsiyet ve tümör lokalizasyonu ile sağ kalım arasında anlamlı fark saptanmamıştır. Günümüzde maksimum cerrahi rezeksiyon ve ardından adjuvan kemoradyoterapi, GBM yönetiminin temel standardı olup, ortalama 12 aylık genel sağ kalım sağlamaktadır. Birçok yeni tedavi rejiminin gelişimine rağmen bu hastalığın tedavisi için henüz gerçekçi bir adjuvan tedavi mevcut değildir. Ne yazık ki, yıllar içerisinde sadece genel hayatta kalma oranlarında minimal bir kazanç sağlanmıştır.

\section{Kaynaklar}

1. Jigisha P. Thakkar, Therese A. Dolecek, Craig Horbinski, Quinn T. Ostrom, Donita D. Lightner, Jill S. Barnholtz-Sloan, and John L. Villano1. Epidemiologic and Molecular Prognostic Review of Glioblastoma. Cancer Epidemiology, Biomarkers \& Prevention 2014; DOI: 10.1158/1055-9965.EPI-14-0275.

2. M Ghosh, S Shubham, K Mandal, V Trivedi, R Chauhan, S Naseera. Survival and prognostic factors for glioblastoma multiforme: Retrospective single-institutional study. Indian Journal of Cancer; 2017;54/1:362-7.

3. Tomasz Tykocki, Mohamed Eltayeb. Ten-year survival in glioblastoma. A systematic review. Journal of Clinical Neuroscience 2018), https://doi.org/10.1016/j.jocn.2018.05.002.

4. Roger Stupp, M.D., Warren P. Mason, M.D., Martin J. van den Bent, M.D., Michael Weller, M.D., Barbara Fisher, M.D., Martin J.B. Taphoorn, M.D., Karl Belanger, M.D., Alba A. Brandes, M.D., Christine Marosi, M.D., Ulrich Bogdahn, M.D., Jurgen Curschmann, M.D., Robert C. Janzer, M.D., Samuel K. Ludwin, M.D., Thierry Gorlia, M.Sc., Anouk Allgeier, Ph.D., Denis Lacombe, M.D., J. Gregory Cairncross, M.D., Elizabeth Eisenhauer, M.D., and Rene O. Mirimanoff, M.D. Radiotherapy plus Concomitant and Adjuvant Temozolomide for Glioblastoma. The new england journal of medicine, 2005; 352:987-96.

5. Supapan Witthayanuwat, Montien Pesee, Chunsri Supaadirek, Narudom Supakalin, Komsan Thamronganantasakul, Srichai Krusun. Survival Analysis of Glioblastoma Multiforme. Asian Pac J Cancer Prev, 2018;19(9):2613-7.

6. A Report of the Medical Research Council Brain Tumour Working Party. Prognostic factors for high-grade malignant glioma: Development of a prognostic index; Journal of Neuro-Oncology, 1990;9: 47-55.

7. Johnson DR, Ma DJ, Buckner JC, Hammack JE. Conditional probability of longterm survival in glioblastoma. Cancer 2012;118:5608-13. https://doi.org/ 10.1002/cncr.27590.

8. Polley M-YC, Lamborn KR, Chang SM, Butowski N, Clarke JL, Prados M. Conditional probability of survival in patients with newly diagnosed glioblastoma. J Clin Oncol 2011;29:4175-80. https://doi.org/10.1200/ JCO.2010.32.4343.

9. FG Davis, BJ McCarthy, S Freels, etal: The conditional probability of survival of patients with primary malignant brain tumors Cancer 85: 485- 91,1999 Crossref, Medline, Google Scholar

10. Anderson E, Grant R, Lewis SC, Whittle PIR. Randomized Phase III controlled trials of therapy in malignant glioma: where are we after 40 years? $\mathrm{Br} J$ Neurosurg 2008;22:339-49. https://doi.org/10.1080/02688690701885603.

11. Mitchell $P$, Ellison DW, Mendelow AD. Surgery for malignant gliomas: mechanistic reasoning and slippery statistics. Lancet Neurol 2005;4:413-22. https://doi.org/10.1016/S1474-4422 (05) 70118-6.

12. Willems PWA, Taphoorn MJB, Burger H, Berkelbach van der Sprenkel JW, Tulleken CAF. Effectiveness of neuronavigation in resecting solitary intracerebral contrast-enhancing tumors: a randomized controlled trial. $J$ Neurosurg 2006;104:360-8. https://doi.org/10.3171/jns.2006.104.3.360.

13. Louis DN, Ohgaki H, Wiestler OD, Cavenee WK, Burger PC, Jouvet A, et al. The 2007 WHO classification of tumours of the central nervous system. Acta Neuropathol. 2007;114:97-109. (PMC free article) (PubMed) (Google Scholar).

14. Abacıoğlu U, Çetin İ, Akgün Z, Şengöz M, Türk Onkoloji Dergisi, Cilt 19, Sayı 3, 2004;112-118. 